Научная статья

УДК $911.2(571.54)$

DOI $10.18101 / 2587-7143-2021-3-56-63$

\title{
НАЛЕДИ В ДОЛИНАХ МАЛЫХ РЕК ЦЕНТРАЛЬНОЙ ЧАСТИ СЕЛЕНГИНСКОГО СРЕДНЕГОРЬЯ: ДИНАМИКА И СОВРЕМЕННОЕ СОСТОЯНИЕ
}

\section{(C) Черных Владимир Николаевич}

младший научный сотрудник,

Байкальский институт природопользования СО РАН

Россия, 670047, г. Улан-Удэ, ул. Сахьяновой, 6

geosibir@yandex.ru

\section{(C) Баир Зугдырович Цыдыпов}

кандидат технических наук, старший научный сотрудник, Байкальский институт природопользования СО РАН Россия, 670047, г. Улан-Удэ, ул. Сахьяновой, 6 bz61@binm.ru

\section{(C) Батор Валерьевич Содномов}

младший научный сотрудник, Байкальский институт природопользования СО РАН Россия, 670047, г. Улан-Удэ, ул. Сахьяновой, 6 sodnomov@binm.ru

\section{(C) Александр Андреевич Аюржанаев}

кандидат технических наук, старший научный сотрудник, Байкальский институт природопользования СО РАН Россия, 670047, г. Улан-Удэ, ул. Сахьяновой, 6 aaayurzhanaev@yandex.ru

Аннотация. В статье приводятся актуальные данные по пространственно-временной динамике и современному состоянию наледей, образующихся в малых водосборных бассейнах постоянных водотоков (малых рек и ручьев) с истоками в отрогах хребта Цаган-Дабан. Установлено, что в зимний период в пределах территории исследования $\left(5700\right.$ км $\left.^{2}\right)$ образуется до 250 небольших наледей, их общая площадь может достигать

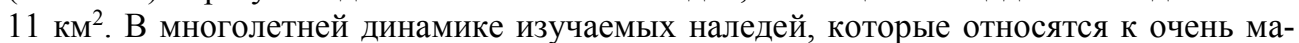
лым и малым, выражена зависимость морфометрии наледных полей от климатических факторов среды. Выполнено картографирование наледей. Полученные результаты могут быть использованы при прогнозировании роста и развития наледей, угрожающих безопасности населенных пунктов.

Ключевые слова: наледь, многолетняя мерзлота, малый водосборный бассейн, дистанционное зондирование Земли, Цаган-Дабан, Селенгинское среднегорье.

\section{Для цитирования}

Наледи в долинах малых рек центральной части Селенгинского среднегорья: динамика и современное состояние / B. H. Черных, Б. 3. Цыдыпов, Б. В. Содномов, A. А. Аюржанаев // Вестник Бурятского государственного университета. Биология, география. 2021. № 3. С. 56-63. 
В. Н. Черных, Б. З. Цыљыпов, Б. В. Содномов, А. А. Аюржанаев. Наледи в долинах малых рек центральной части Селенгинского среднегорья: динамика и современное состояние

Введение. В Селенгинском среднегорье наледи образуются по долинам многочисленных рек в горных частях территории. Наибольшая интенсивность наледеобразования характерна для бассейна р. Джида, для севера и северо-востока (предгорья хребтов Улан-Бургасы, Худанского и др.). Наледи образуются и в центральной части среднегорья. Основной район концентрации наледей здесь это малые водосборные бассейны в отрогах хр. Цаган-Дабан, окружающие его небольшие мезо-кайнозойские межгорные котловины.

Несмотря на то, что работ по наледям Сибири и Дальнего Востока достаточно много $[1 ; 6]$, наледи данного района недостаточно изучены, т. к. по своим морфометрическим характеристикам они небольшие, практически не привлекают внимание исследователей, хотя и играют важное значение в формировании стока малых рек, выполняют экосистемную функцию, а также в отдельных случаях оказывают негативное воздействие на жизнь и хозяйственную деятельность человека, являясь причиной подтоплений.

Целью данного исследования было картографирование наледей в малых водосборных бассейнах центральной части Селенгинского среднегорья с выявлением общих закономерностей их развития, пространственно-временной динамики и современного состояния. Работа выполнялась в рамках изучения наледей на обширной территории бассейна р. Селенги и предполагала, с одной стороны, актуализацию теоретических представлений о процессах наледеобразования в горных районах в связи с климатическими изменениями, наблюдающимися в последние годы, с другой - имела практическое значение с точки зрения обоснования необходимости обеспечения гидроэкологической безопасности отдельных территорий.

Территория исследования. Район исследования выделен в пределах центральной части Селенгинского среднегорья и включает в себя малые водосборные бассейны водотоков, сток которых формируется в западных отрогах хр. Цаган-

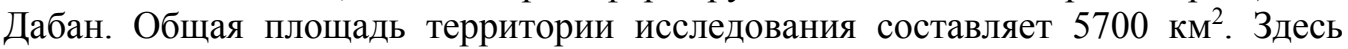
формируется сток малых рек (Куйтунка, Брянка, Сутай и др.), которые относятся к бассейнам рек Селенги, Уды и Тугнуй. Выбор территории исследования обусловлен несколькими факторами. Во-первых, данный район характеризуется одинаковыми на всей площади гидрогеологическими условиями. Согласно гидрогеологическому районированию ${ }^{1}$, территория относится к Цаган-Дабанскому бассейну трещинных вод, которые здесь имеют как инфильтрационное, так и глубинное происхождение. Это определяет особенности питания наледей и их некоторую зависимость от климатических условий. Во-вторых, в этой части Селенгинского среднегорья (как и в бассейне р. Джида) распространена островная многолетняя мерзлота [3; 4], что само по себе определяет вероятность возникновения наледей. В-третьих, на данной территории в недавнем прошлом неоднократно наблюдались случаи подтопления наледями населенных пунктов и инженерно-технических сооружений.

\footnotetext{
${ }^{1}$ Гидрогеологическая карта Бурятской АССР. Масштаб 1:1:1500000 / под редакцией А. И. Ефимова. Москва, 1966. Текст: непосредственный.
} 
На карте (рис. 1) представлен район исследования, цифрами обозначены ключевые участки, наледи в долине р. Воровка (1 и 2), а также район в верховьях р. Куналейка.

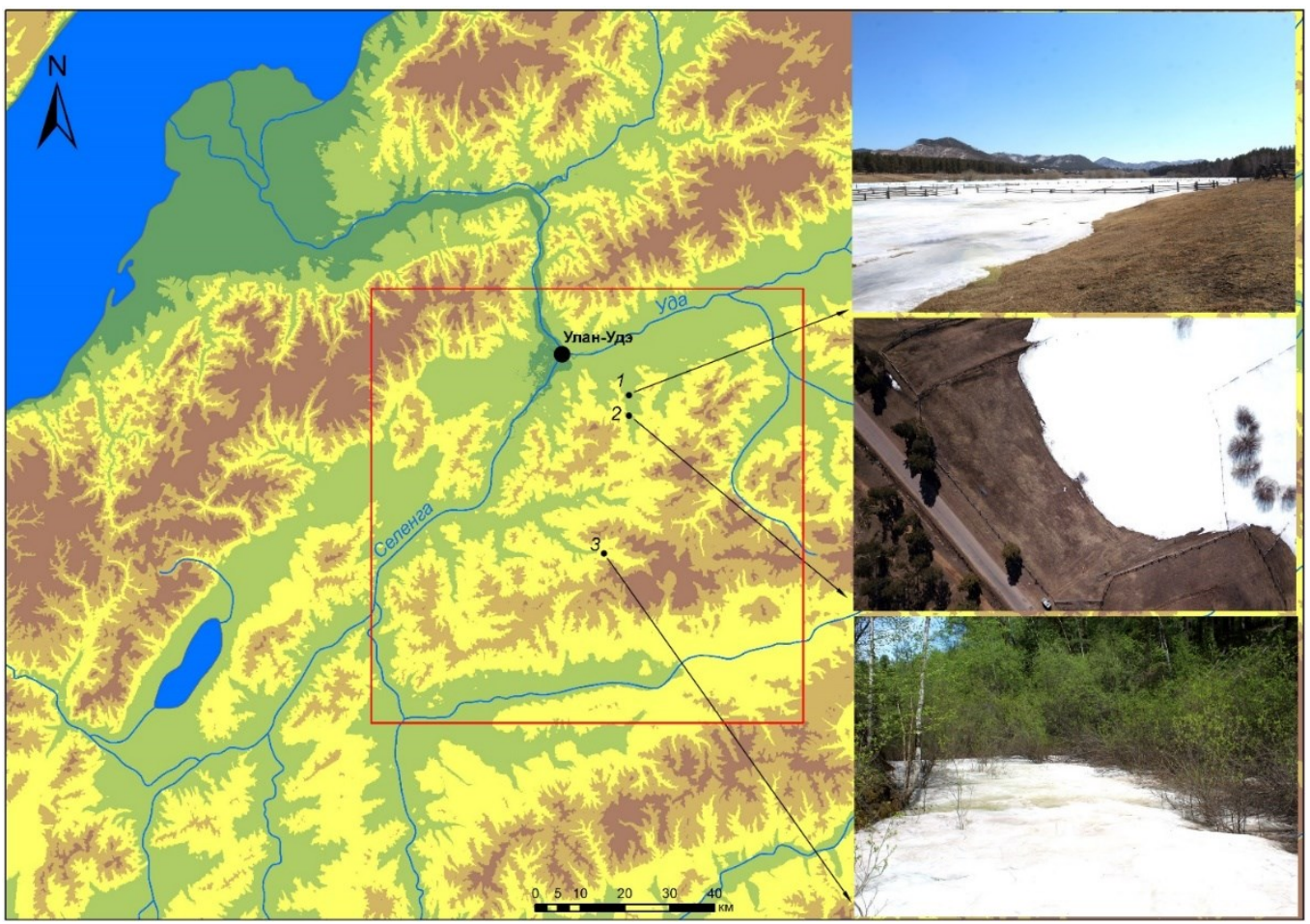

Рис. 1. Обзорная карта района исследования. На фото (сверху вниз): наледь в районе пос. Николаевский, фото наледи с беспилотника, наледь в верховьях р. Куналейка

Материалы и методы. При изучении наледей, формирующихся в зимний период в долинах небольших постоянных водотоков, использованы разновременные мультиспектральные космические снимки Landsat 4-5, Landsat-8. С сервера Национальной геологической службы США (https://earthexplorer.usgs.gov/) подбирались снимки за период с 1991 по 2021 г. В работе анализировались данные космической съемки за март-апрель с максимально близкими датами для разных лет в целях минимизации погрешностей при выделении наледей. Дешифрирование снимков проводилось с использованием алгоритмов расчета стандартизованного индекса различий снежного покрова (Normalized Difference Snow Index NDSI), известного также как снежно-ледовый индекс [10]. Расчет NDSI проведен в растровом калькуляторе ГИС-пакета ArcGIS по формуле:

NDSI $=($ Green - SWIR $) /($ Green + SWIR $)$,

где Green - яркость пикселя в зеленом канале, a SWIR - в коротковолновом инфракрасном канале. При работе со снимками Landsat 4-5 в расчетах используются диапазоны Band 2 и Band 5, для Landsat-8 - Band 3 и Band 6.

Обычно при выделении наледей предварительно создается маска воды и по долинам рек выделяется буфер. Это необходимо для облегчения процесса де- 
В. Н. Черных, Б. З. Цыљыпов, Б. В. Содномов, А. А. Аюржанаев. Наледи в долинах малых рек центральной части Селенгинского среднегорья: динамика и современное состояние

шифрирования, так как полностью автоматизированный способ отделения ледяных полей наледей от снега и других природных объектов, похожих по спектральным характеристикам, пока не разработан. В данном случае этого не проводилось, поскольку площадь территории исследования небольшая, а объекты имеют незначительный размер; потому основная часть работы выполнялась экспертным методом [8]. Определенные сложности возникают в процессе подбора снимков для ретроспективного обзора. Ограничивающими факторами в этом случае выступают облачность и отсутствие продукта для необходимой даты (конец апреля - начало марта). В работе использовано 20 сцен.

Полевые экспедиционные исследования включали съемку наледей на ключевом участке в долине p. Воровка с использованием беспилотного летательного аппарата и наземной лазерной сканирующей станции Leica ScanStation C10, a также наблюдения за интенсивностью таяния наледи в лесном поясе в долине p. Куналейка с помощью автоматических камер фотофиксации.

Результаты и обсуждение. Наледи, образующиеся в долинах небольших водотоков, характеризуются относительной изменчивостью. В зависимости от природно-климатической обстановки из года в год меняются их общее количество, расположение, площади. В охватываемых исследованием хронологических рамках наибольшее количество наледей - 232 - наблюдалось в 2007 г., наименьшее - 61 - в 2013 г. Максимальная суммарная площадь наледей составляла 11,1 км$^{2}$ (2003), минимальная - 2,15 км² (2017). Наледность территории, таким образом, колеблется в пределах от 0,03 до $0,17 \%$, что является невысоким показателем. Так, в бассейне р. Джида, наледность может достигать $0,45 \%$, что сравнимо с северо-востоком России с той лишь разницей, что на реках Якутии и Чукотки образуются гигантские наледи, а на территории Селенгинского среднегорья преобладают малые.

Наледи изучаемого района в подавляющем большинстве малые и средние по площади (от 0,0001 до 0,1 км²). В 2021 г. наибольшая по размерам наледь терри-

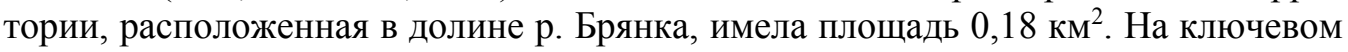
участке исследования в долине р. Воровка наледи могут иметь протяженность до 1 км при максимальной ширине 300-350 м. Мощность ледяного массива на данном участке в 2021 г. достигала 1,7 м.

Многолетняя динамика наледей выражается в изменении их морфометрических характеристик под влиянием климатических факторов. В отличие от крупных наледей, гигантских наледей-тарынов, широко распространенных на северовостоке России [5], небольшие наледи реагируют на смену природной обстановки. Поскольку наледи изучаемого района питаются подземными водами преимущественно инфильтрационными по происхождению (кроме районов установленных разломов), то количество осадков становится определяющим фактором. На рисунке 2 представлены карты, иллюстрирующие многолетнюю динамику числа наледей (рис. 2а) и изменение площадей (рис. 2б).

Рассматриваемый в работе период включает окончание многоводного цикла (начало 2000-х гг.), маловодный период и начало нового этапа увеличения водности (с 2018 г.) [9]. В этот период происходит сокращение площадей наледей до минимума, который пришелся на 2017 г. Начиная с 2018 г. наблюдается незначительное увеличение, которое в будущем, вероятно, продолжится. Изменение ин- 
тенсивности наледеобразования происходит не синхронно с динамикой количества осадков, т. к. увеличению объемов льда в наледях предшествует процесс накопления запасов подземных вод и наоборот, но в целом происходящие изменения отражают климатическую обстановку.

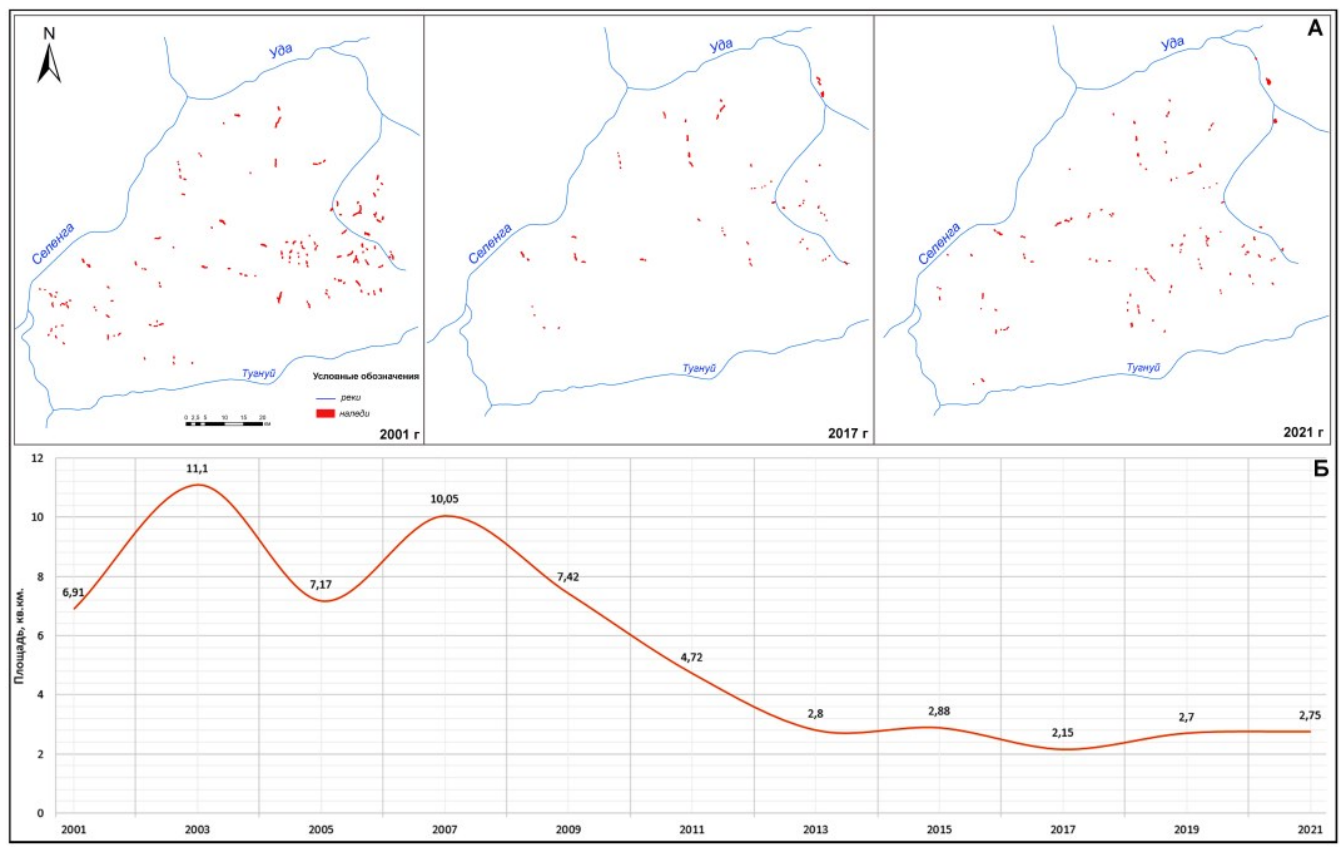

Рис. 2. Динамика наледей: а) карты многолетней динамики;

б) изменение суммарной площади наледей

Общие закономерности таяния наледей также хорошо изучены и описаны в литературе [2; 7]. На данной территории таяние начинается в среднем в конце марта, заканчивается в начале - середине июня в зависимости от мощности наледей, погодных условий и расположения объектов. В лесной зоне таяние происходит в более поздние сроки. В ходе исследования экспериментально установлено, что наледи в нешироких V-образных долинах небольших водотоков в тайге хр. Цаган-Дабан начинают активно таять при температуре выше $+7{ }^{\circ} \mathrm{C}$. В интервале температур от +7 до $+14{ }^{\circ} \mathrm{C}$ наледи теряют мощность до 2 см поверхностного слоя в сутки. Таким образом, в таежной зоне исследуемой территории даже малые и очень малые наледи могут таять до конца июня, обеспечивая тем самым сток в наиболее засушливый период начала лета.

В настоящее время при изучении наледей в малых водосборных бассейнах наиболее актуальным становится вопрос прогнозирования интенсивности развития наледных полей и возникновение в связи с этим чрезвычайных ситуаций. Подтопление наледными водами населенных пунктов на изучаемой территории является важной проблемой обеспечения безопасности населения. Так, в период высокой интенсивности наледеобразования, который наблюдался последний раз в 1996-1999 гг., в пределах рассматриваемой территории подтапливались села Большой Куналей, Бурнашево, Тарбагатай, Старая Брянь, Верхний Саянтуй и др., 
В. Н. Черных, Б. З. Цыдыпов, Б. В. Содномов, А. А. Аюржанаев. Наледи в долинах малых рек центральной части Селенгинского среднегорья: динамика и современное состояние

а также некоторые автодороги республиканского значения, отдельные районы в г. Улан-Удэ. В большинстве указанных населенных пунктов и на объектах инфраструктуры еще с советских времен для защиты от наледей использовались инженерно-технические сооружения, дамбы с перекрывающимися шлюзами для накопления наледи в безопасных для населения участках речных долин, защитные дамбы вдоль русел рек, но за период маловодья, когда интенсивность наледеобразования в долинах рек существенно снизилась, многие сооружения пришли в негодность, а про саму угрозу забыли. Прошедшие зимы 2020 и 2021 гг. показали, что наблюдается устойчивая тенденция к росту площади наледных полей, а значит скоро проблема вновь станет актуальной. Уточнение зависимости интенсивности наледеобразования от количества осадков, сумм отрицательных температур в условиях современного изменения климата позволит прогнозировать масштабность явления и, значит, своевременно принимать меры по минимизации последствий.

Заключение. В результате проведенных исследований впервые для указанной территории составлены карты расположения наледей. На них выделяются как постоянные, образующиеся из года в год в одних и тех же местах, так и периодически появляющиеся, часто смещающиеся вдоль русел рек. Применение космических снимков среднего разрешения для выделения наледей, малых и очень малых по площади, показало свою эффективность для небольших по площади территорий, хотя данный подход, несмотря на использование NDSI, отличается некоторой субъективностью.

Дистанционными методами с применением мультиспектральных космических снимков Landsat установлено, что за последние 20 лет в пределах территории исследования снизилась интенсивность наледеобразования. В малых водосборных бассейнах в отрогах хр. Цаган-Дабан образуется до 232 наледей. Данный максимум интенсивности зафиксирован в 2007 г., но он не является абсолютным. Так, на снимках 1998 г. на территории выделяется более 600 небольших снежноледовых объектов. В настоящее время (2021 г.) в долинах рек территории зафиксировано 167 наледей, общая площадь их составляет всего около 2,7 км².

Существенного роста площадей наледей с начала многоводного цикла, в период с 2018 по 2020 г., в пределах территории исследования не зафиксировано. Тем не менее наблюдается тенденция к росту (рис. 2). В 2021 г. на рассматриваемой территории под угрозой затопления наледями оказались жилые дома и строения в пос. Забайкальский (пригород г. Улан-Удэ), где активное развитие наледи шло на руч. Бойдонов, в районе с. Верхний Саянтуй (там наледь подошла к жилым домам). До подтопления участка автодороги республиканского значения в долине р. Воровка 30 марта 2021 г. оставалось всего 35 см. Лето 2021 г. отличается значительно большим количеством осадков, чем в 2020 г., а это значит, что при прочих равных условиях площади и объемы наледей весной 2022 г. увеличатся.

Наледи как объекты геокриологической и гидрологической природы, являясь частью окружающей среды, подвержены изменениям, происходящим в ней под действием природных и антропогенных факторов. Именно поэтому необходим не только мониторинг наледей, но и их изучение. Особенно это касается районов, 
где наледи не только выполняют экосистемные функции, но и являются потенциально опасными явлениями для жилой инфраструктуры.

\title{
Литература
}

1. Алексеев В. Р. Наледеведение: словарь-справочник. Новосибирск: Изд-во СО РАН, 2007. 438 с. Текст: непосредственный.

2. Арэ Ф. Э. Скорость таяния наледей в центральной Якутии // Наледи Сибири Москва: Наука. 1969. С. 154-160. Текст: непосредственный.

3. Баженова О. И. Современная денудация предгорных степных равнин. Новосибирск: Гео, 2018. 259 с. Текст: непосредственный.

4. Геокриология СССР: Горные страны юга Сибири / под редакцией Э. Д. Ершова. Москва: Недра, 1989. Т. 3. 360 с. Текст: непосредственный.

5. Наледи бассейна реки Индигирка по современным снимкам Landsat и историческим данным / О. М. Макарьева, А. Н. Шихов, А. А. Осташов, Н. В. Нестерова // Лед и снег. 2019. Т. 59, № 2. С. 201-212. Текст: непосредственный.

6. Наледи Сибири и Дальнего Востока: сборник научных трудов. Новосибирск: Наука, 1981. 244 с. Текст: непосредственный.

7. Соколов Б. Л. Наледи и речной сток. Ленинград: Гидрометеоиздат, 1975. 190 с. Текст: непосредственный.

8. Шихов А. Н., Герасимов А. П., Пономарчук А. И. Тематическое дешифрирование и интерпретация космических снимков среднего и высокого пространственного разрешения: учебное пособие / Пермский государственный национально-исследовательский университет. Пермь, 2020. 192 с. Текст: непосредственный.

9. Assessment of the Spatial and Temporal Variability of Arid Ecosystems in the Republic of Buryatia / E. Zh. Garmaev, A. A. Ayurzhanaev, B. Z. Tsydypov [et al.] // Arid Ecosystems. 2020. Vol. 10, №. 2. Р. 114-122. Текст: непосредственный.

10. Zha Y., J. Gao S. Ni. Use of Normalized Difference Built-Up Index in Automatically Mapping Urban Areas from TM Imagery // International Journal of Remote Sensing. 2003. Vol. 24, № 3. Р. 583-594. Текст: непосредственный.

Статья поступила в редакцию 02.09.2021; одобрена после рецензирования 06.09.2021; принята к публикации 01.10.2021.

\section{FLOOD ICING IN SMALL RIVER VALLEYS OF THE CENTRAL PART OF SELENGA HIGHLANDS: THE DYNAMICS AND CURRENT STATE}

\author{
Vladimir N. Chernykh \\ Junior Researcher, \\ Baikal Institute of Nature Management SB RAS \\ 6 Sakhyanovoy St., Ulan-Ude 670047, Russia \\ geosibir@yandex.ru
}

Bair Z. Tsydypov

Cand. Sci. (Engineering), Senior Researcher,

Baikal Institute of Nature Management SB RAS

6 Sakhyanovoy St., Ulan-Ude 670047, Russia

bz61@binm.ru

Bator V. Sodnomov

Junior Researcher,

Baikal Institute of Nature Management SB RAS 
В. Н. Черных, Б. З. Цылдыпов, Б. В. Содномов, А. А. Аюржанаев. Наледи в долинах малых рек центральной части Селенгинского среднегорья: динамика и современное состояние

6 Sakhyanovoy St., Ulan-Ude 670047, Russia

sodnomov@binm.ru

Aleksandr A. Ayurzhanaev

Cand. Sci. (Engineering), Senior Researcher,

Baikal Institute of Nature Management SB RAS

6 Sakhyanovoy St., Ulan-Ude 670047, Russia

aaayurzhanaev@yandex.ru

Abstract. The article presents data on the spatiotemporal dynamics and current state of flood icing formed in the small catchment basins of permanent streams (small rivers and streams) with sources in the spurs of the Tsagan-Daban Ridge. It has been found that during the winter period there are up to 250 small icings formed within the studied territory $\left(5700 \mathrm{~km}^{2}\right)$, their total area can reach $11 \mathrm{~km}^{2}$. The dependence of the morphometry of ice fields on the climatic factors of the environment is reflected in the long-term dynamics of the studied icings, which belong to the very small and small ones. We have performed mapping of flood icing. The obtained results can be used in forecasting the growth and development of icing that threaten the safety of settlements.

Keywords: flood icing, permafrost, small catchment basin, Earth's remote sensing, TsaganDaban, Selenga Highlands.

For citation

Chernykh V. N., Tsydypov B. Z., Sodnomov B. V., Ayurzhanaev A. A. Flood Icing in Small River Valleys of the Central Part of Selenga Highlands: the Dynamics and Current State. Bulletin of Buryat State University. Biology, Geography. 2021; 3: 56-63 (In Russ.).

The article was submitted 02.09.2021; approved after reviewing 06.09.2021; accepted for publication 13.09.2021. 